\title{
A pediatric case of acute localised exanthematous pustulosis triggered by a spider bite
}

\author{
Nadia Nabli, Amina Aounallah, Mohamed Denguezli
}

\author{
Department of Dermatology; Farhat Hached University Hospital, Sousse, Tunisia
}

Corresponding author: Dr. Nadia Nabli, E-mail: nablinadya@gmail.com

Acute localized exanthematous pustulosis (ALEP) is a rare, acute eruption that is related to drug intake in almost $90 \%$ of cases. However, recent findings have underlined the potential implication of viral infections as well as spider bites in this skin condition. Here, we report a particular case of pediatric ALEP triggered by a spider bite and we hope that it will help enlarge the images library of acute and sterile pustular eruptions.

A 5 year-old-patient presented with a two-day history of itchy perineal lesions. His mother reported that he was bitten by a shiny black-colored spider on the left inguinal fold, that she saw but could not capture as she was frightened. She also precised that the spider bite occurred 48 hours before the eruption. Physical examination found perineal swelling with erythema and numerous nonfollicular pustules, some coalescing into lakes of pus with scattered yellowish crusts. These lesions were localized over the lower abdomen, the scrotum and the inner thighs, extending to the gluteal area (Fig. 1). A skin biopsy revealed subcorneal pustules, and inflammatory infiltration in the upper dermis. The patient was diagnosed with acute localized exanthematous pustulosis. Major differentials include pustular eruptions, mainly pustular psoriasis and bacterial infections. Key differentiating features include acute course, history of a trigger factor, and rapid resolution of the lesions. In our case, clinical symptoms and rash were dramatically improved after 3 days of topical Betamethasone Dipropionate 0,05\%, with no recurrence after a 6-moth follow up.

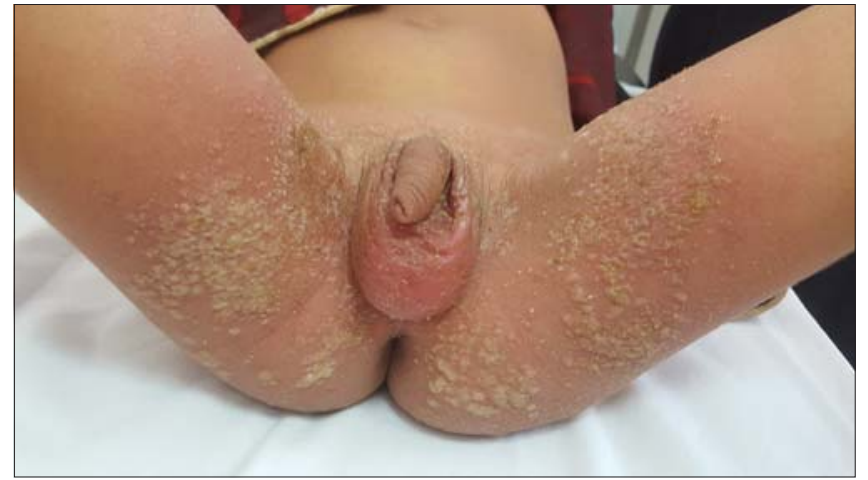

Figure 1 : Perineal swelling with erythema and numerous nonfollicular pustules over the lower abdomen, the scrotum and the inner thighs, extending to the gluteal area.

\section{Consent}

The examination of the patient was conducted according to the Declaration of Helsinki principles.

The authors certify that they have obtained all appropriate patient consent forms. In the form the patient(s) has/have given his/her/their consent for his/her/their images and other clinical information to be reported in the journal. The patients understand that their names and initials will not be published and due efforts will be made to conceal their identity, but anonymity cannot be guaranteed.

Copyright by Nadia Nabli, et al. This is an open access article distributed under the terms of the Creative Commons Attribution License, which permits unrestricted use, distribution, and reproduction in any medium, provided the original author and source are credited.

Source of Support: Nil, Conflict of Interest: None declared.

How to cite this article: Nabli N, Aounallah A, Denguezli M. A pediatric case of acute localised exanthematous pustulosis triggered by a spider bite. Our Dermatol Online. 2020;11(e):e115.1-e115.1.

Submission: $30.03 .2020 ; \quad$ Acceptance: 30.06 .2020

DOI:10.7241/ourd.2020e.115 